\title{
APLICAÇÃO DA METODOLOGIA SEMI-QUANTITATIVA DE AVALIAÇÃO DO RISCO MICROBIOLÓGICO PARA A REUTILIZAÇÃO DE ÁGUA NUM CAMPO DE GOLFE
}

\author{
APPLICATION OF THE SEMI-QUANTITATIVE METHODOLOGY OF MICROBIOLOGICAL RISK \\ ASSESSMENT FOR THE WATER REUSE IN A GOLF COURSE
}

Vanda Sampaio ${ }^{a}$, Ana Silvia Pereira Santos ${ }^{b}$, Manuela Lima ${ }^{a}$

aUniversidade do Minho, 'buniversidade do Estado do Rio de Janeiro

a79807@alunos.uminho.pt, ana.pereira@ueri.br,mmlima@civil.uminho.pt

Submissão: 15 de março de 2021 Aceitação: 1 de julho de 2021

\section{Resumo}

A água é um dos recursos mais valiosos do mundo e embora esteja em constante renovação, a água doce é limitada. Torna-se um recurso ameaçado devido às alterações climáticas e à escassez assim originada, aliado ao rápido crescimento populacional e ao seu desperdício que, por vezes, é incontrolável. Esta situação resulta em graves consequências ambientais, sociais e económicas. Nesse sentido, há a necessidade de encontrar novas alternativas de fontes de água. A reutilização de água com origem em águas residuais tratadas enquadra-se neste tipo de solução pois reduz as necessidades de captação e reforça a recuperação de nutrientes. No presente artigo, a problemática da reutilização de água é abordada com principal interesse em campos de golfe. Através da exposição dos efeitos positivos e negativos nos âmbitos social, ambiental e económico, associadas à utilização de água residual tratada, é aplicada uma metodologia semi-quantitativa de avaliação do risco microbiológico relativamente à saúde pública, num Campo de Golfe, na cidade de Amarante, Porto-Portugal. Primeiramente, recorreu-se a uma avaliação da área em estudo adotando algumas características genéricas, de modo, a obter a estimativa do risco microbiológico para os diferentes recetores e o risco global. O risco global foi de 5,42 e os riscos por recetores variaram entre 3,89 e 6,40; todos classificados como um nível do risco aceitável. Após estes resultados, foram propostas reavaliações, alterando as barreiras e o dano, com o intuito de minimizar o risco global. Dessa forma, conclui-se que o estudo apresenta uma excelente ferramenta técnica de decisão, que permite avaliar vantagens e desvantagens envolvidas às barreiras e risco estimado.

Palavras-chave: Água para reutilização; Campo de golfe; metodologia semi-quantitativa; saúde pública.

\section{Abstract}

Water is one of the most valuable resources in the world and although it is constantly renewing, freshwater is limited. It becomes a threatened resource due to climate change and the scarcity thus created, coupled with rapid population growth and its waste that is sometimes uncontrollable. This situation has serious environmental, social and economic consequences. In this sense, there is a need to find new alternatives for water sources. The water reuse with origin in treated wastewater is part of this kind of solution, as it reduces the collection needs and reinforces the recovery of nutrients. In this article, the problem of reusing water is addressed with the main interest in golf courses. Through the exposure of the positive and negative effects in the social, environmental, and economic, associated with the use of treated wastewater, a semi-quantitative methodology of microbiological risk assessment about public health is applied, in a Golf Course, in the city of Amarante, Porto-Portugal. Previously, a first assessment of the study area was used, adopting some generic characteristics, to obtain the microbiological risk for the different receptors and the global risk. The overall risk was 5,42 and the risk per receptor varied between 3,89 and 6,40; all classified as an acceptable level of risk. After these results, revaluations, changing the barriers and the damage, were proposed to minimize these 
values. Thus, it is concluded that the study presents an excellent technical decision tool, which allows evaluating advantages and disadvantages involved in the barriers and estimated risk.

Keywords: Water reuse; golf course; semi-quantitative methodology, public health.

\section{INTRODUÇÃO}

Outrora, a gestão de águas e resíduos começou a ser utilizada com regularidade, nomeadamente, no armazenamento da água da chuva para a empregar em períodos de seca e o aproveitamento do estrume animal para a fertilização dos solos (ANGELAKIS et al., 2018). A gestão dos recursos hídricos era fundamentada na manipulação do ciclo hidrológico natural com o objetivo de equilibrar a disponibilidade da água pertencente a uma região com base nas suas necessidades sociais e económicas (ASANO, 2015). Apesar dos esforços realizados pelas gerações mais antigas, nos últimos anos verificouse um aumento da pressão sobre os recursos hídricos a nível mundial. Esta pressão resulta do aumento populacional e do crescente consumo de água associado, em particular o relativo ao abastecimento público, à produção agrícola e pecuária, à produção industrial, e ao comércio e diversos serviços de utilização recreativa e desportiva, entre outros (APA, 2019). O objetivo do desenvolvimento e da gestão sustentável dos recursos hídricos é recorrer à utilização da água de forma confiável e equitativa para as gerações atuais e futuras, projetando sistemas adaptáveis, otimizando a eficiência do uso de água, contribuindo para a preservação e a restauração de ecossistemas naturais (ASANO, 2015). Muitas comunidades em todo o mundo estão a aproximarse ou já alcançaram os limites de água disponível e torna-se imprescindível, a recuperação e reutilização da água a partir de água residual tratada para conservar e aumentar 0 abastecimento de água disponível (USEPA, 2004).

As águas residuais são um componente crítico do ciclo da água e que precisa de ser gerido ao longo de todo o ciclo: desde a sua captação, tratamento, distribuição, utilização, recolha e póstratamento para a sua rejeição final no ambiente e/ou reutilização (WWAP, 2017). A reutilização da água é empregue principalmente onde 0 abastecimento de água disponível já se comprometeu e não é possível corresponder às necessidades crescentes de água numa comunidade em constante crescimento. Além disso, oferece uma alternativa de abastecimento de água que está disponível de forma consistente mesmo durante os anos de seca, para vários usos. À escassez de água, acrescenta-se a degradação dos recursos de água doce resultantes da rejeição inadequada de águas residuais (ASANO, 2015).

$A$ água para reutilização $(A p R)$ surge, assim, como uma estratégia para solucionar problemas de carácter ambiental, social e económico, podendo ainda contribuir para a recuperação do estado do ambiente tanto quantitativamente, limitando os volumes de água captados, como qualitativamente, reduzindo as descargas em zonas sensíveis (DRE, 2019). Contrastando com outras fontes de abastecimento de água, como a dessalinização ou a construção de novas barragens, a reutilização de água requer menores custos de investimento e energia. Contribui ainda para reduzir as emissões de gases com efeito de estufa, possibilita o desenvolvimento de projetos que possam afetar as disponibilidades hídricas, e por fim, reduz os efeitos de escassez e secas (APA, 2019).

De maneira geral, a ApR pode ser classificada, de acordo com o uso, em potável e não potável. A ApR potável, segundo Angelakis et al. (2018), pode ainda ser classificada como de uso direto ou indireto, sendo que este último se pode designar como planeado ou não planeado (de facto). Entre ApR de usos não potáveis, Santos e Vieira (2020) identificam as águas para reutilização em rega (paisagística e agrícola), para aquicultura, para aplicação industrial e a nível urbano. Os usos urbanos não potáveis, tais como proteção contra incêndio; sistemas de arrefecimento ou climatização, descarga de autoclismos; rega de zonas relvadas, jardins, parques públicos e campos de golfe; lavagem de veículos; lavagem de ruas e lavagem em máquinas de lavar roupa, apresentam maior simplicidade de manuseamento e gestão, podendo conferir menor risco de contaminação (SANTOS e VIEIRA, 2020).

Observa-se que a ApR é uma fonte atrativa para rega, nomeadamente, para as necessidades das plantas, contribuindo igualmente para a sua fertilização (ALVES, 2008). Dessa forma, em Portugal, dentro dos padrões de rega, são assumidos critérios de qualidade para agricultura, jardins públicos ou privados, campos desportivos e ambientes urbanos, pois para cada tipo de utilização há condições específicas que devem ser 
garantidas a depender do tipo de rega e cultura (SANTOS e VIEIRA, 2020; ALVES, 2008).

As maiores dificuldades associadas à $A p R$ residem nos seus custos, na aceitação pública $\mathrm{e}$ na gestão do risco para garantir a saúde da população (DUONG e SAPHORES, 2015). As águas residuais, mesmo tratadas, contêm ainda alguns microrganismos em concentrações tanto mais reduzidas quando mais elevado for o nível de tratamento, acarretando consequentemente, um aumento do custo desse tratamento. A saúde pública é garantida se houver um tratamento adequado, no sentido de remover agentes patogénicos e compostos químicos tóxicos. De forma a garantir a segurança à população, devese optar por limitar a exposição do público às águas residuais tratadas, quer por contacto, inalação ou ingestão (APA, 2019).

Surge, então, uma nova abordagem denominada fit-for-purpose (adequado para o fim) que, para além do desenvolvimento de um projeto de reutilização adequado a cada situação, sustentado por normas e decretos-lei associados a especificidades locais do ponto de aplicação das águas e das características ambientais, tem como objetivo uma avaliação do risco (ISO, 2020; APA, 2019). Essa avaliação tem como finalidade identificar e avaliar os riscos para a saúde pública associados à ApR para determinar se os perigos são facilmente controlados, informando assim a entidade competente para identificar melhorias e atualizações necessárias com o objetivo de diminuir o nível do risco (WHO, 2016).

Existem várias abordagens para conseguir uma avaliação dos riscos que possa responder às necessidades da sua gestão, segundo WHO (2016), tais como: a) inspeção sanitária, que é uma abordagem simples e eficaz para pequenos fornecimentos de água; b) matriz do risco, que permite avaliar diferentes riscos associados à qualidade da água e que concebe uma avaliação qualitativa e semi-quantitativa da probabilidade de ocorrência de um perigo e da sua gravidade ou consequência caso aconteça, resultando numa classificação do risco; c) análise quantitativa do risco microbiológico (AQRM), que é uma abordagem mais formal que as anteriores e que combina o conhecimento científico sobre a presença e natureza dos agentes patogénicos, o seu potencial destino e transporte no ciclo da água e os cenários de exposição referentes aos intervenientes e os seus efeitos na saúde que resultam dessa exposição.

Diante das possibilidades apresentadas de avaliação dos riscos, o objetivo do presente trabalho é aplicar a metodologia de avaliação semi-quantitativa do risco microbiológico para a implantação de sistemas de ApR para rega num campo de golfe. Nesse contexto, cinco cenários foram produzidos e avaliados com 0 intuito de identificar alternativas para os tomadores de decisão. Ainda, uma nova alternativa com todas as características definidas nas anteriores também foi avaliada. O estudo da sustentabilidade da ApR foi baseado em orientações e legislação Portuguesa.

\section{REUTILIZAÇÃO DE ÁGUA EM CAMPOS DE GOLFE}

A ApR, numa escala global, é predominantemente aplicada no setor de rega agrícola, que consome cerca de $65 \%$ de recursos hídricos utilizados (ASANO, 2015). De seguida, e por ordem decrescente, surgem a rega paisagística (também destinada a campos de golfe), a reutilização para usos industriais (sobretudo em reciclagem de água de arrefecimento), a recarga de aquíferos, os usos recreativos e ambientais e, por fim, os usos urbanos (ERSAR, 2010).

Em Portugal, observa-se um grande interesse pela ApR para a rega de campos de golfe, pois a indústria do turismo é um dos setores económicos que mais se encontra em desenvolvimento (PEREIRA, 2009). As profundas mudanças que ocorreram na indústria do turismo despertaram o interesse em expandir atividades recreativas alternativas além da recreação aquática costeira (MUJERIEGO e SALA, 1991). Por essa razão há a necessidade de aumentar o nível de segurança e o controlo dos processos de tratamento para obter uma melhor qualidade do efluente final (PEREIRA et al., 2010). Em Portugal, o consumo médio anual de rega em campos de golfe de 18 buracos é de $0,3 \mathrm{hm}^{3}$, valor este que pode duplicar no mês em que haja maior necessidade de rega (ERSAR, 2010).

O método de rega mais comum em campos de golfe é por aspersão. Por esse motivo, deve-se evitar a colmatação dos aspersores (PEREIRA, 2009). Os sistemas subterrâneos gota-a-gota estão a tornar-se mais populares, nomeadamente, para tees e greens devido à alta eficiência de rega e, o facto de o contacto humano ser muito limitado. Os lagos e lagoas podem ser usados para armazenamento de ApR e integrados no campo de golfe para permitir obstáculos desafiadores aos jogadores (ASANO, 2015). Para evitar o 
crescimento de algas nestes lagos e lagoas é necessário proceder ao tratamento terciário. Um inconveniente desta ação é a perda de valor fertilizante do efluente a reutilizar (ERSAR, 2010).

Os tipos de relva presentes nos campos de golfe, na sua maioria, são tolerantes à salinidade até $3 \mathrm{dS} / \mathrm{m}$. Apesar desta não ser uma característica controversa, deve ser tida em conta devido à relva dos tees e dos greens ser mais pisada e, sujeita a um grande movimento. Nesses locais para a preservação da relva pode se obrigar à instalação de um sistema de drenagem para a prevenção da salinidade do solo (ERSAR, 2010). Deve-se garantir uma conveniente alimentação hídrica de toda a relva de forma a não degradar as propriedades físicas, químicas e biológicas do solo (PEREIRA, 2009). A ApR utilizada na rega de campos de golfe requer um tratamento terciário para garantir que a água seja segura para a saúde dos golfistas devido à alta concentração de indicadores fecais no seu efluente (ERSAR, 2010). No Quadro 1 apresentam-se as principais características que afetam a qualidade da água para rega de campos de golfe.

Quadro 1: Características que afetam a qualidade da água para rega de campos de golfe

\begin{tabular}{|c|c|c|}
\hline Características & $\begin{array}{l}\text { Parâmetros de } \\
\text { avaliação }\end{array}$ & Efeito \\
\hline $\begin{array}{l}\text { Sólidos em } \\
\text { suspensão }\end{array}$ & SST & $\begin{array}{l}\text { Concentrações de SST podem levar ao desenvolvimento de } \\
\text { deposição de sólidos, condições anaeróbias, reduzir a } \\
\text { permeabilidade do solo e provocar a obstrução dos sistemas de } \\
\text { rega. }\end{array}$ \\
\hline $\begin{array}{l}\text { Salinidade, sais } \\
\text { inorgânicos } \\
\text { dissolvidos }\end{array}$ & $\begin{array}{l}\text { SDT, } \\
\text { elétrica, } \\
\text { específicos (elementos } \\
\mathrm{Ca}, \mathrm{Mg}, \mathrm{Cl}, \mathrm{B})\end{array}$ & $\begin{array}{l}\text { Salinidade excessiva causa danos à cultura. } \mathrm{Na}, \mathrm{B}, \mathrm{Cl} \text { podem ser } \\
\text { tóxicos para as plantas. O ião } \mathrm{Na}^{+} \text {pode provocar problemas de } \\
\text { permeabilidade do solo. }\end{array}$ \\
\hline $\begin{array}{l}\text { Matéria orgânica } \\
\text { biodegradável }\end{array}$ & $\mathrm{CBO}, \mathrm{CQO}$ & $\begin{array}{l}\text { A decomposição destes compostos pode levar ao consumo da } \\
\text { totalidade do oxigénio dissolvido nas águas e ao } \\
\text { desenvolvimento de condições sépticas. }\end{array}$ \\
\hline $\begin{array}{l}\text { Compostos } \\
\text { orgânicos } \\
\text { refractários }\end{array}$ & $\begin{array}{l}\text { Compostos } \\
\text { específicos (fenóis, } \\
\text { pesticidas, } \\
\text { hidrocarbonetos } \\
\text { halogenados) }\end{array}$ & $\begin{array}{l}\text { Apresentam resistência aos métodos convencionais do } \\
\text { tratamento de efluentes. Alguns destes compostos são tóxicos } \\
\text { para o ambiente e a sua presença pode limitar a utilização da } \\
\text { água para rega. }\end{array}$ \\
\hline Nutrientes & $\begin{array}{l}\text { Azoto, } \\
\text { Potássio }\end{array}$ & $\begin{array}{l}\text { São nutrientes essenciais para o crescimento das plantas e a sua } \\
\text { presença geralmente encarece o valor da água para rega. } \\
\text { Também podem provocar o crescimento de vida aquática } \\
\text { indesejável quando aplicados no solo em grandes quantidades. } \\
\text { Quando o azoto é descarregado em grandes quantidades pode } \\
\text { provocar a poluição das águas subterrâneas. }\end{array}$ \\
\hline $\begin{array}{l}\text { Atividade } \\
\text { hidrogeniônica }\end{array}$ & $\mathrm{pH}$ & $\begin{array}{l}\mathrm{O} \mathrm{pH} \text { das águas residuais afeta a solubilidade dos metais bem } \\
\text { como a alcalinidade dos solos. }\end{array}$ \\
\hline Metais pesados & $\begin{array}{l}\mathrm{Cd} ; \mathrm{Cr} ; \mathrm{Cu} ; \mathrm{Fe} ; \mathrm{Hg} ; \mathrm{Ni} \\
\mathrm{Zn}\end{array}$ & $\begin{array}{l}\text { Alguns metais pesados acumulam-se no ambiente e são tóxicos } \\
\text { para as plantas e para os animais. Podem limitar a aplicação das } \\
\text { águas residuais para rega. }\end{array}$ \\
\hline Cloro residual & $\mathrm{Cl}$ livre, $\mathrm{Cl}$ combinado & $\begin{array}{l}\text { Quantidade excessiva de cloro livre pode causar queimaduras } \\
\text { nas folhas e danificar culturas sensíveis Como a maior parte de } \\
\text { cloro nas águas residuais tratadas (ART) está na forma } \\
\text { combinada não causa danos às culturas. No entanto, existe } \\
\text { alguma preocupação no que diz respeito aos efeitos tóxicos dos } \\
\text { organoclorados em relação à contaminação das águas } \\
\text { subterrâneas. }\end{array}$ \\
\hline $\begin{array}{l}\text { Microrganismos } \\
\text { patogénicos }\end{array}$ & $\begin{array}{l}\text { Organismos } \\
\text { indicadores de } \\
\text { contaminação fecal e } \\
\text { helmintas }\end{array}$ & Transmissão de doenças. \\
\hline
\end{tabular}

Fonte: Adaptado de PETTYGROVE e ASANO (1987); PEREIRA (2009); ERSAR (2010).

Legenda: SST (Sólidos Suspensos Totais); SDT (Sólidos Dissolvidos Totais); Na (Sódio); Ca (Cálcio); Mg (Magnésio); $\mathrm{Cl}$ (Cloro); B (Boro); $\mathrm{CBO}$ (Carência Bioquímica de Oxigénio); CQO (Carência Química de Oxigénio); pH (potencial Hidrogeniónico); Cd (Cádmio); $\mathrm{Cr}$ (Crómio); Cu (Cobre); Fe (Ferro); Hg (Mercúrio); Ni (Níquel); Zn (Zinco). 


\section{POTENCIALIDADES, BENEFÍCIOS E RISCOS ASSOCIADOS À ApR}

A reutilização é uma das opções viáveis para a gestão sustentável das águas residuais. Os benefícios da ApR (Quadro 2) são numerosos e incluem a redução da pressão sobre os abastecimentos de água doce, minimizando a descarga de efluentes em águas superficiais ou costeiras. O fornecimento e uso de ApR podem desempenhar um papel importante na melhoria do abastecimento de água para uso urbano em muitas partes do mundo com escassez hídrica. As características desta água dependem da sua fonte, nível de tratamento e localização geográfica, podendo ser classificadas de acordo com o seu aspeto físico, químico e biológico. $\mathrm{O}$ aspeto biológico é importante pois permite avaliar os efeitos na saúde pública. As características físicas e químicas são cruciais para compreender os efeitos ambientais do uso da água residual tratada (MAHESHWARI et al., 2016).

No caso do risco associado à ApR, ressaltase a relevância do microbiológico para a saúde humana. Nesse sentido, torna-se imprescindível a necessidade da avaliação desse risco, que permite identificar a sua criticidade para a segurança de um projeto de reutilização de água e auxiliar na procura das soluções mais adequadas (APA, 2019). Portanto, o processo de avaliação do risco precisa, de alguma forma, de os classificar ou quantificar em termos de impacto na saúde WHO (2016). Assim, o risco microbiológico pode ser obtido através da equação 1 , segundo a APA (2019).

O processo de avaliação do risco inicia-se com a identificação dos perigos, ou seja, de forma a reconhecer os agentes que provocam e influenciam um dano à saúde pública. Os perigos microbiológicos que, normalmente, são considerados no processo de avaliação do risco são os microrganismos de contaminação fecal que causam danos à saúde pública; em geral $E$. coli (Escherichia coli). Este é considerado o indicador mais adequado de contaminação fecal, quando comparado com outros como coliformes fecais ou totais, visto ser incapaz de se multiplicar no ambiente e ser facilmente detetável mesmo em elevada diluição. Por se encontrar em elevado número no trato intestinal, existem valores recomendados em normas legais para a qualidade da água microbiana para o uso de água para vários fins urbanos não potáveis (APA, 2019; ChhipiShrestha et al., 2017). No Quadro 3 são identificados os níveis de perigo em função do tipo de tratamento e os respetivos padrões de $E$. coli, de acordo com a APA (2019), ISO (2020) e Rebelo et al. (2020) assim como a correspondente classificação numa escala de 1 a 9. Para esses respetivos níveis apresentam-se, na Figura 1, os processos de tratamento associados ao alcance da qualidade desejada para a ApR.

A remoção de azoto e fósforo estão em destaque na Figura 1 , já que não estão necessariamente relacionados com a qualidade da $A p R$, inclusive em caso de irrigação fértil, o azoto e o fósforo devem permanecer no efluente como insumos para produtividade agrícola.

Observando a Figura 1, pode-se inferir que à medida que o nível de perigo diminui, o tipo de tratamento é mais exigente, e consequentemente mais dispendioso. É importante adaptar o nível de tratamento ao fim pretendido (conceito fit-forpurpose), porque nem sempre o mais rigoroso é, efetivamente $o$ adequado pois certos constituintes presentes na água podem vir a ser úteis na aplicação de ApR. Dessa forma, é imprescindível controlar e monitorizar os parâmetros microbiológicos presentes no efluente, para aplicar o tratamento adequado para o fim proposto.

Para se obter a vulnerabilidade para o cálculo do risco microbiológico, é importante primeiro identificar as vias de exposição e caracterizar os cenários de exposição avaliando as suas probabilidades de ocorrência. As vias de exposição podem ser diretas, estando em contacto direto com a ApR, e indiretas, estando em contacto indireto com microrganismos que possam estar presentes na ApR (APA, 2019). Os cenários de exposição são considerados mediante o local, o tipo de ocupação e organização do espaço em estudo, que introduzem um risco a cada recetor. É nesta etapa que se cruzam os possíveis recetores com as vias de exposição correspondentes. Os recetores são os agentes que estão mais suscetíveis a ter contacto com a ApR e que podem ser divididos em pessoas mais expostas ao risco (utilizadores, trabalhadores, idosos, crianças, etc.) e animais.

$$
\text { Risco microbiológico }=\text { Perigo } * \text { Vulnerabilidade } * \text { Dano } \quad \text { Equação } 1
$$


Quadro 2: Benefícios ambientais, sociais e económicos associados à ApR

\begin{tabular}{|ll|}
\hline \multicolumn{1}{|c|}{ Benefícios } & \multicolumn{1}{c|}{ Conceito } \\
\hline \multirow{3}{*}{ Ambientais } & $\begin{array}{l}\text { Conservação das fontes de água doce, principalmente em zonas com stress } \\
\text { hídrico associado, ou seja, locais onde a procura e a oferta dos recursos } \\
\text { hídricos entram em discrepância. }\end{array}$ \\
\hline & $\begin{array}{l}\text { Gestão de nutrientes que podem levar à degradação ambiental. } \\
\text { Maior proteção dos ambientes aquáticos, pela redução direta das cargas } \\
\text { poluentes rejeitadas. }\end{array}$ \\
\hline A ApR contém nutrientes que levam à diminuição da utilização de \\
fertilizantes artificiais na rega de terras agrícolas contribuindo, assim, para o \\
crescimento da cultura sem prejudicar o ambiente.
\end{tabular}

Fonte: (Adaptado de ASANO (2015); CATARINO (2018); WHO (2016); SANTOS (2008).

Quadro 3: Níveis de perigo associados à prática de reutilização

\begin{tabular}{|lccc|}
\hline \multicolumn{1}{|c}{ Tipo de tratamento } & Nível & $\begin{array}{c}\text { Presença de E.Coli } \\
\text { (UFC } / \mathbf{1 0 0 m L})\end{array}$ & Classificação \\
\hline Secundário & V & $\geq 10^{4}$ & 9 \\
\hline Secundário + Desinfecção & IV & $10^{3}<$ E.coli $<10^{4}$ & 7 \\
\hline Avançado & III & $10^{2}<$ E.coli $\leq 10^{3}$ & 5 \\
\hline Secundário + desinfecção + pós-cloragem & II & $10^{1}<$ E.coli $\leq 10^{2}$ & 3 \\
\hline Avançado + pós-cloragem & I & E.coli $\leq 10^{1}$ & 1 \\
\hline
\end{tabular}

Fonte: APA (2019), ISO (2020) e (Rebelo et al., 2020).

Para terminar o cálculo do risco microbiológico, segue-se a determinação do dano. Para cada cenário de exposição devem ser identificados os tipos de barreira. A barreira equivalente surge como uma medida de controlo capaz de originar um resultado semelhante a uma redução microbiológica, e consequentemente eliminar um determinado perigo ou até mesmo reduzi-lo até um nível aceitável. As barreiras têm como objetivo reduzir a exposição ao contacto direto com a ApR, e consequentemente diminuir os impactos sobre a saúde. Estas podem ser aplicadas a montante, sobre, e a jusante do sistema de produção de ApR. Podem ser utilizadas individualmente ou em conjunto, e neste caso, denominam-se multibarreira. $\mathrm{O}$ dano, portanto, é determinado com base na probabilidade de falha nas barreiras (APA, 2019; Rebelo et al., 2020).

Além do risco microbiológico associado à $A p R$ ressaltam-se outros. Em relação ao ambiente os poluentes ainda remanescentes na $A p R$, tais como, microrganismos patogénicos, nutrientes, sólidos, metais, micropoluentes e outros, podem trazer consequências danosas. Para além disto, destacam-se as dificuldades de aceitação do público, os custos de transporte por camião- 
cisterna ou adução em função das distâncias entre produtores e utilizadores da ApR, eventual necessidade de otimização da ETAR para adequação do efluente à exigência requerida para o uso pretendido e, por fim, há que se ter em conta a necessidade de identificação e separação entre as redes de abastecimento de água para consumo humano e de ApR.

Figura 1: Processos de tratamento associados ao alcance da qualidade desejada para a ApR

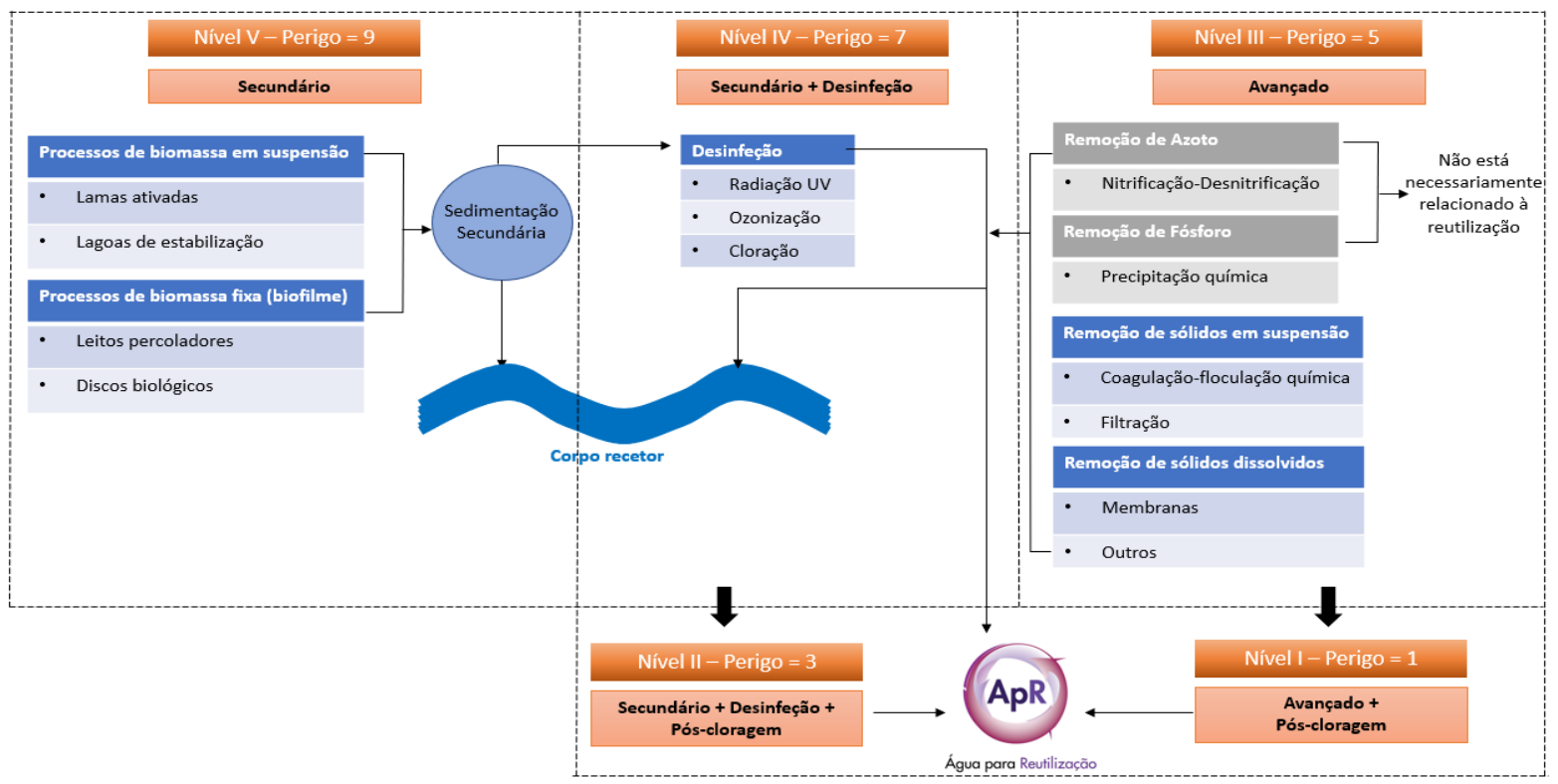

Fonte: Adaptado de PETTYGROVE e ASANO (1987); EWA e APESB (1998).

\section{METODOLOGIA}

O presente trabalho foi realizado em duas etapas, a partir da aplicação da metodologia semiquantitativa do risco microbiológico (MSqRM) para utilização de ApR no campo de Golfe de Amarante (CGA). A área de estudo da presente pesquisa, o CGA, localiza-se no concelho de Amarante, pertencente ao distrito do Porto e nas proximidades do distrito de Braga e concelho de Guimarães, conforme pode ser observado no mapa de localização da Figura 2.

O CGA, foi inaugurado em 1997, encontra-se a $600 \mathrm{~m}$ acima do nível do mar, apresenta uma área total de aproximadamente 40 hectares e oferece 18 buracos, envolvidos com espaços relvados extensos, vegetação arbórea e 4 lagos (GOLFE AMARANTE, 2021). Nas Figuras 3 e 4, observam-se o desenho esquemático e uma fotografia da unidade de estudo, respetivamente.

A MSqRM foi aplicada para a reutilização de água no CGA em duas etapas: i) na primeira foram adotadas características iniciais, que levaram a determinados valores do risco aos recetores e valores do risco global; ii) na segunda, com a intenção de reduzi-los, foram realizadas reavaliações iterativas considerando alterações nas barreiras e nos fatores de importância. $\mathrm{Na}$ Figura 5, observa-se o fluxograma definido pelas autoras para a realização das etapas de aplicação da MSqRM, que envolveram a adoção do perigo, a definição dos recetores, a estimativa de vulnerabilidade de cada recetor e a determinação do dano a partir das barreiras definidas no modelo. Posteriormente, procedeu-se à estimativa do risco para cada recetor e para o risco global (etapa 1), por fim, foram realizadas as reavaliações iterativas a partir do mesmo processo (etapa 2).

\section{Etapa 1: Aplicação da MSqRM (1ª avaliação)}

As principais características adotadas pelas autoras para o desenvolvimento da $1^{\underline{a}}$ avaliação estão descritas no Quadro 4.

Observação: A barreira b) (pós-cloragem) refere-se à cloração no reservatório antes da aplicação.

- As características de acesso e de funcionamento, foram definidas em função das práticas atuais adotadas na administração do CGA.

- O Perigo foi definido a partir das indicações da APA (2019) e ISO (2020), conforme 
observa-se no Quadro 4.

- As características de exposição dos recetores estão apresentadas no Quadro 5.

- As vias de exposição foram adotadas a partir da indicação de APA (2019) e ISO (2020).

- A definição dos cenários de exposição, bem como os fatores de importância a eles atribuídos são consideradas tarefas bastante subjetivas e foram realizadas pelos autores, considerando outras experiências (REBELO, 2018; APA, 2019).

- Diante da definição dos cenários e das vias de exposição, além da atribuição dos fatores de importância, calculou-se a vulnerabilidade de cada recetor, a partir da equação 2.

- As barreiras também foram adotadas pelas autoras, como input da aplicação da metodologia. O dano global foi determinado a partir da relação entre a probabilidade de falha na barreira e a severidade do dano parcial, conforme matriz representada na Figura 6 e equações 3 e 4 .

- Por fim, os riscos por recetor e global foram estimados de acordo com as equações 5 e 6.

Figura 2: Mapa de localização do CGA, objeto do presente caso de estudo.

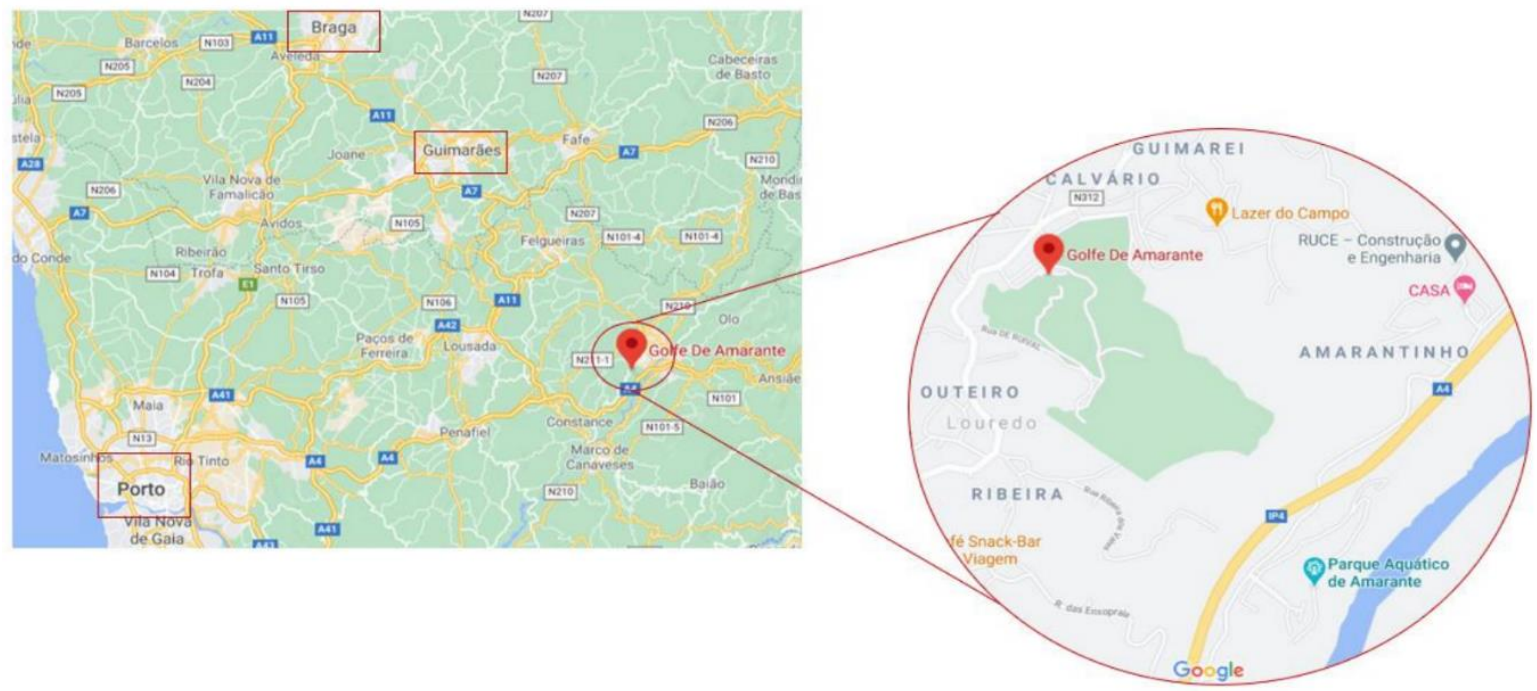

Fonte: Elaborado pelas autoras a partir de Google Maps.

\begin{tabular}{|l|l|}
$\begin{array}{c}\text { Figura 3: Desenho esquemático do } \\
\text { CGA. }\end{array}$ & Figura 4: Fotografia do CGA. \\
\hline & \\
\hline
\end{tabular}


Figura 5: Fluxograma das etapas de aplicação da MSqRM

Etapa 1: Aplicação da MSqRM (1a Avaliação)

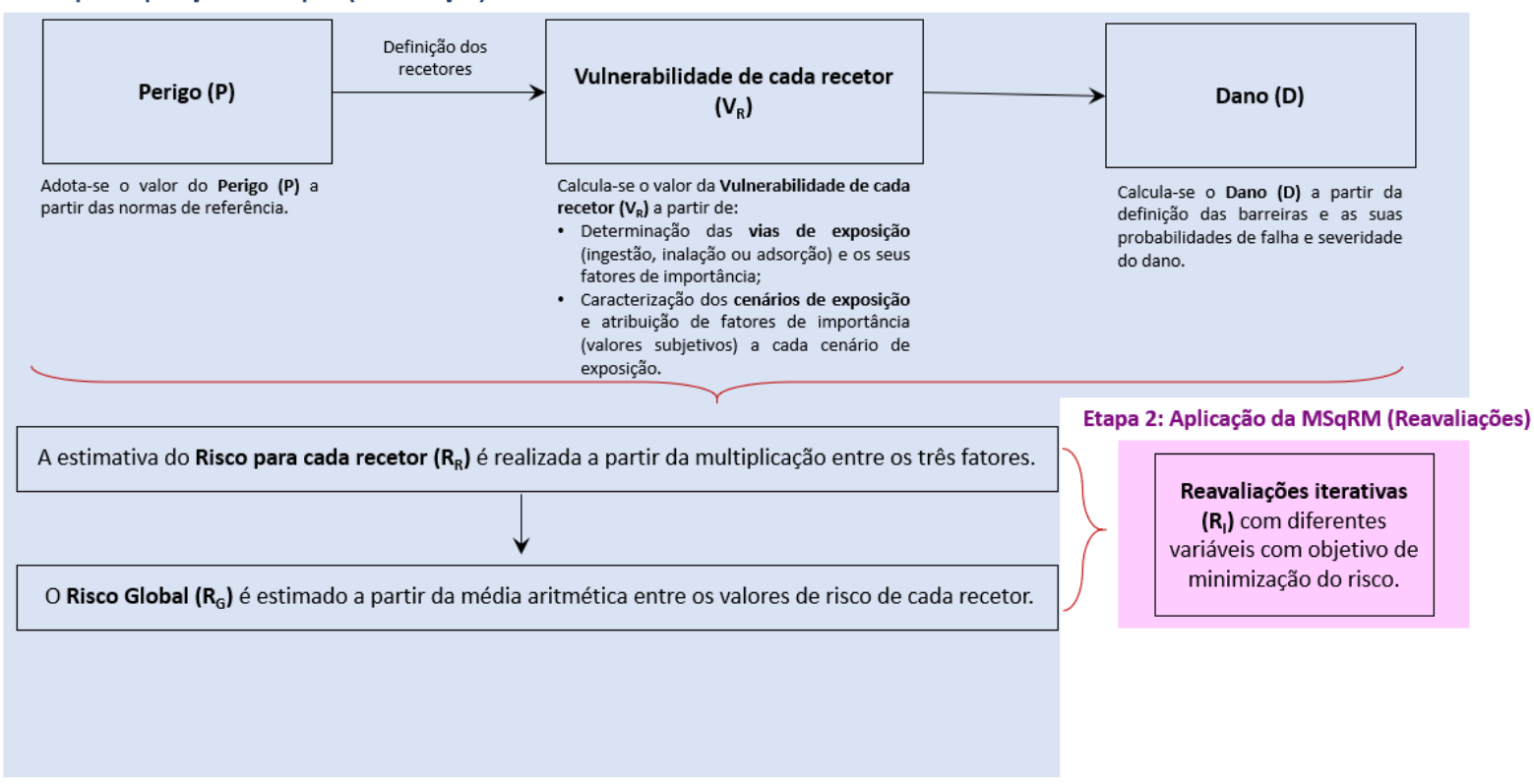

Fonte: Elaborado pelas autoras.

Quadro 4: Características adotadas na $1^{\text {a }}$ avaliação da MSqRM

\begin{tabular}{|c|c|}
\hline 1ª avaliação $^{\text {a }}$ & Características \\
\hline Acesso & Restrições de acesso somente a animais de companhia. \\
\hline Funcionamento & Aberto ao público das $9 \mathrm{~h}$ às $19 \mathrm{~h}$. \\
\hline Perigo & E. coli $=10^{3}$ a $10^{4} \mathrm{UFC} / 100 \mathrm{~mL}$ (Perigo 7 ) \\
\hline Recetores & $\begin{array}{l}\text { Trabalhadores, jogadores, visitantes. Os visitantes são divididos em } \\
\text { crianças e adolescentes e adultos. }\end{array}$ \\
\hline Vias de exposição & Ingestão, inalação ou adsorção. \\
\hline Cenários de exposição & $\begin{array}{l}\text { a) Ingestão da água durante a rega (via direta); b) Ingestão do solo com o } \\
\text { contacto com o equipamento de golfe (via indireta); c) Inalação de } \\
\text { aerossóis durante a rega (via direta); d) Adsorção por contacto direto com } \\
\text { a ApR (via direta); e) Adsorção por contacto com sistema de rega (via } \\
\text { direta); f) Adsorção por contacto com vegetação (via direta); g) Adsorção } \\
\text { por contacto com o equipamento de golfe com o solo (via indireta). }\end{array}$ \\
\hline $\begin{array}{l}\text { Fatores de importância } \\
\text { para os cenários de } \\
\text { exposição }\end{array}$ & $\begin{array}{l}\text { Via de infecção demonstrada (9); Via de infecção possível (7); Eventual via } \\
\text { de infecção (5); Ausência de dados sobre a via de infecção (3); Ausência } \\
\text { de via de infecção demonstrada (1). }\end{array}$ \\
\hline Barreiras & $\begin{array}{l}\text { a) Rega por aspersão; b) Pós-cloragem; c) Restrição de acesso durante } \\
\text { as horas de rega no campo de golfe (sem horário específico). }\end{array}$ \\
\hline Níveis do risco & $\begin{array}{l}0<\mathrm{R}_{\text {global }}<3 \text { (risco desprezável); } 3 \leq \mathrm{R}_{\text {global }}<7 \text { (risco aceitável); } 7 \leq \mathrm{R}_{\text {global }} \\
<9 \text { (risco inaceitável) }\end{array}$ \\
\hline
\end{tabular}

Fonte: Elaborado pelas autoras 


\section{Quadro 5: Função dos recetores adotados no estudo}

\begin{tabular}{|c|c|c|}
\hline Recetores & & Funções \\
\hline \multirow{6}{*}{ Trabalhadores } & Jardineiros & $\begin{array}{l}\text { Manutenção do jardim procedendo ao seu corte, arranjo, } \\
\text { podas, limpeza dos relvados e ancinhar bunkers. Ter em } \\
\text { consideração todas as áreas relacionadas ao campo de } \\
\text { golfe }\end{array}$ \\
\hline & $\begin{array}{l}\text { Assistente de } \\
\text { programação e } \\
\text { manutenção de } \\
\text { sistemas de rega }\end{array}$ & $\begin{array}{l}\text { Realizar a programação dos vários sistemas de rega, a } \\
\text { sua respetiva manutenção e reparação. }\end{array}$ \\
\hline & $\begin{array}{l}\text { Instrutores ou } \\
\text { professores de golfe }\end{array}$ & $\begin{array}{llll}\text { Ensinar } & \text { e transmitir conhecimentos aos seus } \\
\text { aprendizados de qualquer idade. } & & \\
\end{array}$ \\
\hline & $\begin{array}{l}\text { Gestor de } \\
\text { equipamentos }\end{array}$ & $\begin{array}{l}\text { Entrega de equipamentos aos jogadores e } \\
\text { posteriormente a sua recolha no campo de golfe se } \\
\text { necessário. }\end{array}$ \\
\hline & Caddie $^{*}$ & $\begin{array}{l}\text { Carregador da bolsa com os tacos do golfista e mediante } \\
\text { as suas competências mais avançadas pode servir para } \\
\text { indicar a posição das bolas durante o jogo. }\end{array}$ \\
\hline & $\begin{array}{l}\text { Referee ou juiz } \\
\text { árbitro* }\end{array}$ & $\begin{array}{l}\text { Acompanha os jogadores e decide qual a regra a aplicar } \\
\text { em caso de transgressão. }\end{array}$ \\
\hline Jogadores & Em contato perma & com o campo \\
\hline
\end{tabular}

Fonte: Elaborado pelas autoras

Observação: * apenas são aplicados em casos de competições ou campeonatos de golfe.

De seguida, apresentam-se as equações que foram implementadas para a obtenção dos níveis do risco para a etapa 1 e 2 do presente caso de estudo.

- $V_{\text {recetor }}=\frac{\sum\left(f i_{\text {via exp }} x f i_{\text {cen exp }}\right)}{f_{\text {normalização }}}$

Equação 2

Onde:

$f i_{\text {viaexp }}$

$=$ fator de exposição de cada via de exposição

$f i_{\text {cenexp }}$

= fator de importância de cada cenário de exposição

$f_{\text {normalização }}=$ fator de normalização

- Dano $=\frac{\sum\left(d_{i} * n\right)}{f_{\text {normalização }}}$

Equação 3

Onde:

$d_{i}=$ danos parciais $=$

severidade dos danos*probabilidade de falha

$\mathrm{n}=$ número de barreiras equivalentes conforme retratado na Norma ISO 16075 - 2:2015

- $f_{\text {normalização }}=f_{i_{\text {máx }}} * \sum\left(f_{i_{\text {via exp }}} n^{\mathrm{o}} \operatorname{cen} \exp _{i}\right.$ Equação 4

Onde:

$f_{i_{\text {máx }}}$

= valor máximo da escala de fatores de importância $\left(f_{i_{\text {máx }}}=9\right)$

$n^{n}$ cen $\exp _{i}$

= número de cenários aplicável a cada receptor

- $R_{\text {recetor }}=$ Perigo $* V_{\text {recetor }} *$ Dano Equação 5

- $R_{\text {Global }}=\frac{\sum R_{\text {Recetor }}}{N_{\text {Recetores }}} \quad$ Equação 6

\section{Etapa 2: Aplicação da MSqRM (Reavaliações iterativas)}

Foram realizadas cinco reavaliações iterativas com as características apresentadas no Quadro 6. 
Figura 6: Matriz de determinação do dano

\begin{tabular}{|c|c|c|c|c|c|c|c|}
\hline & \multicolumn{5}{|c|}{ Probabilidade de falha na barreira } \\
\hline & & & \multirow{2}{*}{$\begin{array}{c}\text { Rara } \\
1 \\
\end{array}$} & \multirow{2}{*}{$\begin{array}{c}\text { Pouco } \\
\text { provável } \\
2 \\
\end{array}$} & \multirow{2}{*}{$\begin{array}{c}\text { Possível } \\
3 \\
\end{array}$} & \multirow{2}{*}{$\begin{array}{c}\text { Provável } \\
4 \\
\end{array}$} & \multirow{2}{*}{$\begin{array}{c}\begin{array}{c}\text { Quase } \\
\text { certa }\end{array} \\
5 \\
\end{array}$} \\
\hline & & & & & & & \\
\hline \multirow{5}{*}{ 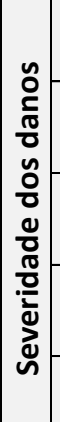 } & Insignificante & 1 & 1 & 1 & 2 & 2 & 3 \\
\hline & Fraco & 2 & 1 & 2 & 4 & 4 & 5 \\
\hline & Moderado & 3 & 2 & 4 & 4 & 6 & 7 \\
\hline & Forte & 4 & 2 & 4 & 6 & 8 & 9 \\
\hline & Severo & 5 & 3 & 5 & 7 & 9 & 9 \\
\hline
\end{tabular}

Fonte: Adaptado de APA (2019).

Quadro 6: Características adotadas em cada reavaliação iterativa

\begin{tabular}{|c|c|}
\hline Reavaliação & Características \\
\hline Reavaliação 1 & $\begin{array}{l}\text { Barreiras adotadas: } \\
\text { a) Rega por aspersão; } \\
\text { b) Pós-cloragem; } \\
\text { c) Restrição de acesso durante as horas de rega fora do horário de utilização. }\end{array}$ \\
\hline Reavaliação 2 & $\begin{array}{l}\text { Encamisamento dos aspersores após a finalização do sistema de rega com as três } \\
\text { barreiras consideradas na Etapa } 1 \text { ( } 1 \text { a } \text { Avaliação). Com isto, alterou-se o fator de } \\
\text { importância do cenário "e" (Adsorção por contacto com sistema de rega). }\end{array}$ \\
\hline Reavaliação 3 & $\begin{array}{l}\text { Esta reavaliação resulta da combinação das reavaliações 1+2, ou seja, as barreiras } \\
\text { adotadas são: } \\
\text { a) Irrigação por aspersão implementando um encamisamento dos mesmos no final } \\
\text { da rega (esta prática leva à alteração do fator de importância do cenário e) tal como } \\
\text { aconteceu na Reavaliação 2); } \\
\text { b) Pós-cloragem; } \\
\text { c) Restrição de acesso durante as horas de rega fora do horário de utilização. }\end{array}$ \\
\hline Reavaliação 4 & $\begin{array}{l}\text { Sugestão de um acréscimo da capacitação e utilização de equipamentos de } \\
\text { proteção individual (EPI’s) (utilização de um fato impermeável, luvas e máscara) } \\
\text { na classe de recetores dos trabalhadores. Nesta fase, alteraram-se os fatores de } \\
\text { importância dos cenários de exposição apenas dos trabalhadores. No que diz } \\
\text { respeito ao dano, consideraram-se as três barreiras adotadas na Etapa } 1 \text { (1aㅡ } \\
\text { Avaliação). }\end{array}$ \\
\hline Reavaliação 5 & $\begin{array}{l}\text { Semelhante à Reavaliação } 4 \text {, mas com o valor do dano que se obteve na } \\
\text { Reavaliação 1. As barreiras adotadas são as mesmas da Reavaliação } 1 \text {, mas } \\
\text { implementando uma capacitação e utilização de EPI`s na classe dos trabalhadores } \\
\text { que vai sofrer alterações dos fatores de importância, como desenvolvido na } \\
\text { reavaliação anterior. }\end{array}$ \\
\hline
\end{tabular}

Fonte: Elaborado pelas autoras

\section{RESULTADOS E DISCUSSÃO}

De maneira análoga à metodologia, os resultados serão apresentados no contexto das Etapas 1 e 2.

\section{Etapa 1: Aplicação da MSqRM (1ª avaliação)}

Nas Tabelas 1, 2, 3 e 4 estão apresentados os resultados das cenarizações para os recetores trabalhadores, jogadores, visitantes (crianças e 
adolescentes) e visitantes (adultos), respectivamente, incluindo-se 0 cálculo da vulnerabilidade de cada recetor conforme indicado pela equação 2 .

Observa-se que os valores obtidos nos cálculos de vulnerabilidade são lógicos. Os trabalhadores são os recetores que estão mais sujeitos aos riscos e apresentam um valor de vulnerabilidade superior ao dos restantes, de 0,91. De seguida, os jogadores são os mais afetados apresentando um valor de 0,85 . Os visitantes são os recetores que menos estão expostos ao perigo. Como os visitantes estão divididos entre dois grupos (crianças e adolescentes, adultos) e visto que os primeiros são a classe mais vulnerável e inconsciente apresentam um valor superior ao dos adultos, 0,78 e 0,56 respetivamente. Ainda assim, apresentam um valor inferior ao dos jogadores em virtude de se tratar de visitantes, não estando expostos permanentemente ao perigo.

Em relação ao dano, para todas as barreiras apresentadas, considera-se uma probabilidade de falha na barreira "quase certa" e uma severidade de danos de nível "severo", traduzindo num dano parcial de importância absoluta de valor igual a 9, conforme a matriz de determinação do dano (Figura 6). Dessa forma, de acordo com a Equação 3 , o dano apresentou valor igual a 1.

Tabela 1: Resultado da cenarização para o recetor "trabalhadores"

\begin{tabular}{|c|c|c|c|c|}
\hline $\begin{array}{l}\text { Cenário } \\
\text { exposição }\end{array}$ & $\begin{array}{c}\text { Fator } \\
\text { importância } \\
\left(f i_{\text {cen exp }}\right)\end{array}$ & Justificação & $\begin{array}{c}\text { Via } \\
\text { exposição } \\
\left(f i_{\text {viaexp }}\right)\end{array}$ & $f i_{\text {via exp }} \times f i_{\text {cen exp }}$ \\
\hline $\mathrm{a}$ & 9 & Elevada para todos os trabalhadores & 9 & 81 \\
\hline $\mathrm{b}$ & 9 & $\begin{array}{c}\text { Contacto sempre direto com o } \\
\text { equipamento }\end{array}$ & 9 & 81 \\
\hline $\mathrm{c}$ & 9 & Rega por aspersão & 9 & 81 \\
\hline$d$ & 9 & $\begin{array}{l}\text { Sempre elevada para os } \\
\text { trabalhadores }\end{array}$ & 3 & 27 \\
\hline e & 5 & $\begin{array}{l}\text { Em caso de problema com } \\
\text { aspersores }\end{array}$ & 3 & 15 \\
\hline$f$ & 7 & $\begin{array}{c}\text { Contacto provável com folhas e } \\
\text { raízes }\end{array}$ & 3 & 21 \\
\hline g & 5 & $\begin{array}{l}\text { Manutenção de equipamento } \\
\text { molhado }\end{array}$ & 3 & 15 \\
\hline Somatório & & & 39 & 321 \\
\hline $\mathrm{V}_{\text {recetor }}$ & & & & 0,91 \\
\hline
\end{tabular}

Tabela 2: Resultado da cenarização para o recetor "jogadores"

\begin{tabular}{|ccccc|}
\hline $\begin{array}{c}\text { Cenário } \\
\text { exposição }\end{array}$ & $\begin{array}{c}\text { Fator } \\
\text { importância } \\
\left(f i_{\text {cen exp }}\right)\end{array}$ & Justificação & $\begin{array}{c}\text { Via } \\
\text { exposição } \\
\left(f i_{\text {viaexp }}\right)\end{array}$ & $f i_{\text {via exp }} x f i_{\text {cen exp }}$ \\
\hline a & - & Não aplicável & - & - \\
\hline b & 9 & $\begin{array}{c}\text { Contacto sempre direto com o } \\
\text { equipamento }\end{array}$ & 91 \\
\hline c & - & Não aplicável & - & - \\
\hline d & - & Não aplicável & - & - \\
\hline e & 5 & Aspersor ainda molhado & 3 & 15 \\
\hline f & 7 & Contacto provável com folhas e raízes & 3 & 21 \\
\hline g & 7 & Equipamento molhado devido ao contacto \\
com o solo & 3 & 15 \\
\hline Somatório & & & 18 & 138 \\
\hline Vrecetor & & & & 0,85 \\
\hline
\end{tabular}


Tabela 3: Resultado da cenarização para o recetor "visitantes (crianças e adolescentes)"

\begin{tabular}{|ccccc|}
\hline $\begin{array}{c}\text { Cenário } \\
\text { exposição }\end{array}$ & $\begin{array}{c}\text { Fator } \\
\text { importância } \\
\left(f i_{\text {cen exp }}\right)\end{array}$ & Justificação & $\begin{array}{c}\text { Via } \\
\text { exposição } \\
\left(f i_{\text {viaexp }}\right)\end{array}$ & $f i_{\text {via exp }} \times f i_{\text {cen exp }}$ \\
\hline a & - & Não aplicável & - & - \\
\hline b & 7 & Equipamento perdido no campo & 9 & 63 \\
\hline c & - & Não aplicável & - & - \\
\hline d & - & Não aplicável & - & - \\
\hline e & 7 & Aspersor ainda molhado & 3 & 21 \\
\hline f & 9 & Brincadeiras na relva & 3 & 27 \\
\hline g & 5 & Equipamento perdido no campo molhado & 3 & 15 \\
\hline Somatório & & & 18 & 126 \\
\hline Vrecetor & & & 0,78 \\
\hline
\end{tabular}

Tabela 4: Resultado da cenarização para o recetor "visitantes (adultos)"

\begin{tabular}{|ccccc|}
\hline $\begin{array}{c}\text { Cenário } \\
\text { exposição }\end{array}$ & $\begin{array}{c}\text { Fator } \\
\text { importância } \\
\left(f i_{\text {cen exp }}\right)\end{array}$ & Justificação & $\begin{array}{c}\text { Via } \\
\text { exposição } \\
\left(f i_{\text {viaexp }}\right)\end{array}$ & $f i_{\text {via exp }} \times f i_{\text {cen exp }}$ \\
\hline a & - & Não aplicável & - & - \\
\hline b & 5 & Equipamento perdido no campo & 9 & 45 \\
\hline c & - & Não aplicável & - & - \\
\hline d & - & Não aplicável & - & - \\
\hline e & 5 & Aspersor ainda molhado & 3 & 15 \\
\hline f & 7 & Contacto provável com folhas e raízes & 3 & 21 \\
\hline g & 3 & Equipamento perdido no campo & 3 & 9 \\
\hline Somatório & & & 18 & 90 \\
\hline$V_{\text {recetor }}$ & & & 0,56 \\
\hline
\end{tabular}

Finalmente, as informações de exposição e efeitos na saúde são combinadas calculando o risco para as condições e cenários definidos durante a caracterização do risco. O resultado desta etapa deve alimentar diretamente as questões de gestão do risco definidas durante a formulação do problema. A análise de incerteza e/ou análise de sensibilidade pode ser extremamente valiosa para testar a robustez dos cálculos do risco para apoiar a decisão de gestão do risco. Assim, foram estimados o risco para cada recetor (equação 5) e o global (equação 6), conforme resultados apresentados na Tabela 5.

Tabela 5: Resultados do risco para cada recetor e global

\begin{tabular}{|lcc|}
\hline \multicolumn{1}{c}{ Recetor } & Risco & Nível do risco \\
\hline Trabalhadores & 6,37 & Aceitável \\
\hline Jogadores & 5,95 & Aceitável \\
\hline Visitantes (crianças e adolescente) & 5,46 & Aceitável \\
\hline Visitantes (adultos) & 3,92 & Aceitável \\
\hline Risco Global & 5,43 & Aceitável \\
\hline
\end{tabular}

Quando o risco apresenta um valor que seja considerado inaceitável, é necessário proceder à reavaliação de todo o processo, ajustando as barreiras de modo a obter níveis do risco desprezável ou aceitável. Se por algum motivo não for possível essa modificação, o projeto não se tornará viável. Entretanto, conforme apresentado na Tabela 5, mesmo o maior risco (6,37 para 
trabalhadores) estando próximo do valor limite (7) para a categoria de inaceitável, todos os valores se apresentaram na faixa do aceitável.

De seguida, apresenta-se a Tabela 6 que funciona como um quadro resumo da caracterização do risco para diferentes níveis de tratamento, ou seja, valores de E. coli variáveis e correspondentes classificações de perigo. Importa referir que, apesar de se ter adotado um valor de perigo igual a 7 numa primeira avaliação, apresentam-se os resultados para os restantes perigos para criar termo de comparação entre todos e, de forma a verificar o que os faz variar. Por estas razões, também se torna uma solução viável para os tomadores de decisão, de modo a verificarem os prós e contras de cada norma de qualidade. Para além disto, este tipo de análise procura ainda contribuir para a maior aceitação social da ApR. De facto, a análise e quantificação detalhada do risco microbiológico, apesar de resultar de uma metodologia simplificada como é a
MSqRM, permite desenvolver informação concreta e dirigida ao público alvo, que poderia de outra forma tender a rejeitar a utilização de espaços de lazer e prática desportiva regados com recurso a ApR.

Observa-se que o risco global só se altera para desprezável a partir do nível de perigo 3, apesar de no nível de perigo 5, no recetor adultos, se apresentar um nível igualmente desprezável. Portanto, o objetivo passa por pretender alcançar níveis do risco desprezáveis a partir do nível de perigo 3 ou 1 , preferencialmente. O motivo é precisamente pelo facto de evitar que o tomador de decisão um valor monetário superior. Isto porque para a classificação de perigo ser cada vez menor, corresponde a um nível de tratamento mais avançado e exigente, o que corresponde a uma maior complexidade operacional aliada a um custo mais elevado. Desta forma, deverão ser aplicadas alternativas para minimizar este risco.

Tabela 6: Resultados do risco para cada recetor e global para diferentes classificações de perigo.

\begin{tabular}{|c|c|c|c|c|c|c|}
\hline $\begin{array}{l}\text { Norma de } \\
\text { qualidade } \\
\text { (E.Coli) } \\
\text { UFC/100mL }\end{array}$ & Perigo & Recetor & Vulnerabilidade & Dano & Risco & $\begin{array}{l}\text { Nível do } \\
\text { risco }\end{array}$ \\
\hline \multirow{5}{*}{$10^{3}-10^{4}$} & \multirow{5}{*}{7} & Trabalhadores & 0,91 & \multirow{4}{*}{1,0} & 6,37 & Aceitável \\
\hline & & Jogadores & 0,85 & & 5,95 & Aceitável \\
\hline & & Crianças/Adolescentes & 0,78 & & 5,46 & Aceitável \\
\hline & & Adultos & 0,56 & & 3,92 & Aceitável \\
\hline & & Global & & & 5,43 & Aceitável \\
\hline \multirow{5}{*}{$10^{2}-10^{3}$} & \multirow{5}{*}{5} & Trabalhadores & 0,91 & \multirow{4}{*}{1,0} & 4,55 & Aceitável \\
\hline & & Jogadores & 0,85 & & 4,25 & Aceitável \\
\hline & & Crianças/Adolescentes & 0,78 & & 3,90 & Aceitável \\
\hline & & Adultos & 0,56 & & 2,80 & Desprezável \\
\hline & & Global & & & 3,88 & Aceitável \\
\hline \multirow{5}{*}{$10^{1}-10^{2}$} & \multirow{5}{*}{3} & Trabalhadores & 0,91 & \multirow{4}{*}{1,0} & 2,73 & Desprezável \\
\hline & & Jogadores & 0,85 & & 2,55 & Desprezável \\
\hline & & Crianças/Adolescentes & 0,78 & & 2,34 & Desprezável \\
\hline & & Adultos & 0,56 & & 1,68 & Desprezável \\
\hline & & Global & & & 2,33 & Desprezável \\
\hline \multirow{5}{*}{$<10$} & \multirow{5}{*}{1} & Trabalhadores & 0,91 & \multirow{4}{*}{1,0} & 0,91 & Desprezável \\
\hline & & Jogadores & 0,85 & & 0,85 & Desprezável \\
\hline & & Crianças/Adolescentes & 0,78 & & 0,78 & Desprezável \\
\hline & & Adultos & 0,56 & & 0,56 & Desprezável \\
\hline & & Global & & & 0,78 & Desprezável \\
\hline
\end{tabular}




\section{Etapa 2: Aplicação da MSqRM (Reavaliações iterativas)}

A Tabela 7 apresenta os resultados de cada uma das reavaliações iterativas, descritas no item metodologia, respectivamente, e de maneira resumida, analogamente à Tabela 6. Optou-se pelo mesmo procedimento anterior, em que se inclui a análise para níveis de perigo inferiores ao destacado no Quadro 5. Isto permite aferir a sensibilidade dos resultados e fornecer a análise técnica que possibilita aos tomadores de decisão avaliar a relevância de promover um nível de tratamento superior ou mais avançado.

Observa-se na Tabela 7 que a reavaliação 1 difere da etapa 1 unicamente na barreira equivalente - Restrição de acesso durante as horas de rega - se realizar fora do horário de utilização. Isto permite diminuir o dano e resulta na redução do risco global de 5,43 para 5,05 , no caso de um nível de perigo 7. A maior vantagem desta alteração reside no facto de ser unicamente uma restrição horária, que não possui um custo associado e de não obrigar a alterar o nível de tratamento para obter um valor do risco inferior.

$\mathrm{Na}$ reavaliação 2, com a utilização de um encamisamento dos aspersores após o sistema de rega, os valores da vulnerabilidade dos recetores diminuem ligeiramente. No entanto, o valor do risco $(5,20)$ aumenta ligeiramente quando comparando com a reavaliação $1(5,05)$, porque o dano interfere mais nos cálculos. Importa sublinhar que apenas houve alteração do fator de importância num único cenário de exposição. A esse fator de importância corresponde o valor 3 na via de exposição, ou seja, por ser um valor tão inferior não há mudanças significativas comparativamente à avaliação realizada inicialmente. Com isto, pode-se concluir que com o dano de valor igual a 1 aliado ao encamisamento dos aspersores, talvez não compense a adoção desta barreira, já que acarreta mais custos e resulta em valores praticamente análogos e insatisfatórios.

$\mathrm{Na}$ reavaliação 3, com a utilização dos encamisamentos dos aspersores com o valor do dano 0,93, ou seja, corresponde à utilização das condições das reavaliações 1 e 2 simultaneamente, já se observa uma alteração substancial dos valores do risco. Assim, o risco global situa-se em 4,83, inferior aos valores de 5,20 e 5,05 das reavaliações 2 e 1 respetivamente, no caso de nível de perigo 7. Portanto, em termos compensatórios, este ajuste seria mais vantajoso do que a reavaliação 2 . Fundamentalmente, a reavaliação 3 avalia as principais vantagens das reavaliações anteriores em conjunto, o que se evidencia como muito viável.

$\mathrm{Na}$ reavaliação 4, em que se optou pela implementação de EPI's e pelo acréscimo da capacitação dos trabalhadores conclui-se que o valor do risco dos trabalhadores diminui consideravelmente para 4,83 (no caso de nível de perigo 7), apesar de apresentar o dano de valor igual a 1 .

Se o tomador de decisão optar pela implementação de EPI's e um acréscimo da capacitação dos trabalhadores, então é aconselhável optar pela reavaliação 5 em vez da anterior. A reavaliação 5 corresponde à utilização das condições das reavaliações 1 e 4 , simultaneamente. Isto permite, para além da alteração dos valores do risco dos trabalhadores modificar igualmente os valores dos restantes recetores, ou seja, consegue abranger todas as classes expostas ao perigo. Como resultado o risco global apresenta um valor de 4,69, ou seja, o menor dos observados no caso de nível de perigo 7.

Globalmente, os resultados da Tabela 7 permitem aos tomadores de decisão aferir a variação do risco global em função das diferentes características das cinco reavaliações, ponderando igualmente a influência de um nível de tratamento superior. Assim observa-se que adotando um nível de tratamento que conduz a um perigo menor ou igual a 3 , ou seja Secundário + desinfeção + pós-cloragem ou Avançado + póscloragem (Quadro 3 e Figura 1), o risco para todos os recetores e o risco global podem ser sempre classificados como desprezáveis. No entanto, a redução do perigo resulta da adoção de um nível de tratamento superior e consequentemente mais dispendioso. Caso o tomador de decisão entenda que é adequado que o risco global se situe na gama de aceitável, correspondente a níveis de perigo superiores ou iguais a 5 , os resultados das reavaliações permitem ajudar à tomada de decisão ponderados os custos inerentes às características de cada reavaliação. O campo de golfe pode selecionar a opção que mais se adequa, desde que a qualidade seja no mínimo classe $B$ (perigo 3) ou classe C conjugada com uma barreira equivalente (perigo 5), tal como o disposto no Decreto-Lei n. ${ }^{\circ} 119 / 2019$, de 21 de agosto.

Como sugestão apresenta-se uma reavaliação mais completa que as restantes, ou seja, contemplando todas as vantagens de todas 
as reavaliações apresentadas anteriormente (Quadro 7). Avaliou-se igualmente os níveis do risco (Tabela 8) para comparar esses valores com os já obtidos anteriormente.

Como se esperava é a reavaliação que apresenta níveis do risco mais baixos. No valor de perigo 7, apresenta um risco global de 4,49 o que se torna muito satisfatório. Cabe ao tomador de decisão determinar a continuação do nível de tratamento IV ou optar por tratamentos mais avançados e assim obter níveis do risco desprezáveis.

\section{Quadro 7: Características adotadas na sugestão da reavaliação}

\begin{tabular}{|l|l|}
\hline \multirow{4}{*}{ Sugestão de Reavaliação } & \multicolumn{1}{c|}{ Características } \\
\cline { 2 - 3 } & a) $\begin{array}{l}\text { O valor do dano de 0,93, ou seja, apresenta três barreiras: } \\
\text { rega por aspersão, pós-cloragem e restrição de acesso } \\
\text { durante as horas de rega fora do horário de utilização; }\end{array}$ \\
\cline { 2 - 3 } & b) $\begin{array}{l}\text { A utilização de encamisamentos em todos os aspersores } \\
\text { após o fim do sistema de rega; }\end{array}$ \\
\hline & c) $\begin{array}{l}\text { A implementação de EPI`s e um acréscimo da capacitação } \\
\text { dos trabalhadores. }\end{array}$ \\
\hline
\end{tabular}

Fonte: Elaborado pelas autoras

Tabela 8: Caracterização do risco para a sugestão de reavaliação

\begin{tabular}{|c|c|c|c|c|c|c|}
\hline $\begin{array}{l}\text { Norma de } \\
\text { qualidade } \\
\text { (E.Coli) } \\
\text { UFC/100mL }\end{array}$ & Perigo & Recetor & Vulnerabilidade & Dano & Risco & $\begin{array}{l}\text { Nível do } \\
\text { risco }\end{array}$ \\
\hline \multirow{5}{*}{$10^{3}-10^{4}$} & \multirow{5}{*}{7} & Trabalhadores & 0,69 & \multirow{4}{*}{0,93} & 4,49 & Aceitável \\
\hline & & Jogadores & 0,81 & & 5,27 & Aceitável \\
\hline & & Crianças/Adolescentes & 0,74 & & 4,82 & Aceitável \\
\hline & & Adultos & 0,52 & & 3,39 & Aceitável \\
\hline & & Global & & & 4,49 & Aceitável \\
\hline \multirow{5}{*}{$10^{2}-10^{3}$} & \multirow{5}{*}{5} & Trabalhadores & 0,69 & \multirow{4}{*}{0,93} & 3,21 & Aceitável \\
\hline & & Jogadores & 0,81 & & 3,77 & Aceitável \\
\hline & & Crianças/Adolescentes & 0,74 & & 3,44 & Aceitável \\
\hline & & Adultos & 0,52 & & 2,42 & Desprezável \\
\hline & & Global & & & 3,21 & Aceitável \\
\hline \multirow{5}{*}{$10^{1}-10^{2}$} & \multirow{5}{*}{3} & Trabalhadores & 0,69 & \multirow{4}{*}{0,93} & 1,93 & Desprezável \\
\hline & & Jogadores & 0,81 & & 2,26 & Desprezável \\
\hline & & Crianças/Adolescentes & 0,74 & & 2,06 & Desprezável \\
\hline & & Adultos & 0,52 & & 1,45 & Desprezável \\
\hline & & Global & & & 1,93 & Desprezável \\
\hline \multirow{5}{*}{$<10$} & \multirow{5}{*}{1} & Trabalhadores & 0,69 & \multirow{4}{*}{0,93} & 0,64 & Desprezável \\
\hline & & Jogadores & 0,81 & & 0,75 & Desprezável \\
\hline & & Crianças/Adolescentes & 0,74 & & 0,69 & Desprezável \\
\hline & & Adultos & 0,52 & & 0,48 & Desprezável \\
\hline & & Global & & & 0,64 & Desprezável \\
\hline
\end{tabular}


Tabela 7: Resultados das reavaliações iterativas

\begin{tabular}{|c|c|c|c|c|c|c|c|c|c|c|c|c|c|c|c|c|c|}
\hline \multirow{2}{*}{$\begin{array}{c}\text { Norma de } \\
\text { qualidade } \\
\text { (E.Coli) } \\
\text { UFC/100mL }\end{array}$} & \multirow[t]{2}{*}{ Perigo } & \multirow[t]{2}{*}{ Recetor } & \multicolumn{3}{|c|}{ Reavaliação 1} & \multicolumn{3}{|c|}{ Reavaliação 2} & \multicolumn{3}{|c|}{ Reavaliação 3} & \multicolumn{3}{|c|}{ Reavaliação 4} & \multicolumn{3}{|c|}{ Reavaliação 5} \\
\hline & & & $\mathrm{V}$ & $\mathrm{D}$ & $\mathrm{R}$ & $\mathrm{V}$ & $\mathrm{D}$ & $\mathrm{R}$ & $\mathrm{V}$ & $\mathrm{D}$ & $\mathrm{R}$ & $\mathrm{V}$ & $\mathrm{D}$ & $\mathrm{R}$ & $\mathrm{V}$ & $\mathrm{D}$ & $\mathrm{R}$ \\
\hline \multirow{5}{*}{$10^{3}-10^{4}$} & \multirow{5}{*}{7} & Trabalhadores & 0,91 & \multirow{4}{*}{0,93} & 5,92 & 0,90 & \multirow{4}{*}{1,00} & 6,30 & 0,90 & \multirow{4}{*}{0,93} & 5,86 & 0,69 & \multirow{4}{*}{1,00} & 4,83 & 0,69 & \multirow{4}{*}{0,93} & 4,49 \\
\hline & & Jogadores & 0,85 & & 5,53 & 0,81 & & 5,67 & 0,81 & & 5,27 & 0,85 & & 5,95 & 0,85 & & 5,53 \\
\hline & & Crianças/Adolescentes & 0,78 & & 5,08 & 0,74 & & 5,18 & 0,74 & & 4,82 & 0,78 & & 5,46 & 0,78 & & 5,08 \\
\hline & & Adultos & 0,56 & & 3,65 & 0,52 & & 3,64 & 0,52 & & 3,39 & 0,56 & & 3,92 & 0,56 & & 3,65 \\
\hline & & Global & & & 5,05 & & & 5,20 & & & 4,83 & & & 5,04 & & & 4,69 \\
\hline \multirow{5}{*}{$10^{2}-10^{3}$} & \multirow{5}{*}{5} & Trabalhadores & 0,91 & \multirow{4}{*}{0,93} & 4,23 & 0,90 & \multirow{4}{*}{1,00} & 4,50 & 0,90 & \multirow{4}{*}{0,93} & 4,19 & 0,69 & \multirow{4}{*}{1,00} & 3,45 & 0,69 & \multirow{4}{*}{0,93} & 3,21 \\
\hline & & Jogadores & 0,85 & & 3,95 & 0,81 & & 4,05 & 0,81 & & 3,77 & 0,85 & & 4,25 & 0,85 & & 3,95 \\
\hline & & Crianças/Adolescentes & 0,78 & & 3,63 & 0,74 & & 3,70 & 0,74 & & 3,44 & 0,78 & & 3,90 & 0,78 & & 3,63 \\
\hline & & Adultos & 0,56 & & 2,60 & 0,52 & & 2,60 & 0,52 & & 2,42 & 0,56 & & 2,80 & 0,56 & & 2,60 \\
\hline & & Global & & & 3,60 & & & 3,71 & & & 3,45 & & & 3,60 & & & 3,35 \\
\hline \multirow{5}{*}{$10^{1}-10^{2}$} & \multirow{5}{*}{3} & Trabalhadores & 0,91 & \multirow{4}{*}{0,93} & 2,54 & 0,90 & \multirow{4}{*}{1,00} & 2,70 & 0,90 & \multirow{4}{*}{0,93} & 2,51 & 0,69 & \multirow{4}{*}{1,00} & 2,07 & 0,69 & \multirow{4}{*}{0,93} & 1,93 \\
\hline & & Jogadores & 0,85 & & 2,37 & 0,81 & & 2,43 & 0,81 & & 2,26 & 0,85 & & 2,55 & 0,85 & & 2,37 \\
\hline & & Crianças/Adolescentes & 0,78 & & 2,18 & 0,74 & & 2,22 & 0,74 & & 2,06 & 0,78 & & 2,34 & 0,78 & & 2,18 \\
\hline & & Adultos & 0,56 & & 1,56 & 0,52 & & 1,56 & 0,52 & & 1,45 & 0,56 & & 1,68 & 0,56 & & 1,56 \\
\hline & & Global & & & 2,16 & & & 2,23 & & & 2,07 & & & 2,16 & & & 2,01 \\
\hline & & Trabalhadores & 0,91 & & 0,85 & 0,90 & & 0,90 & 0,90 & & 0,84 & 0,69 & & 0,69 & 0,69 & & 0,64 \\
\hline & & Jogadores & 0,85 & 0,93 & 0,79 & 0,81 & 1,00 & 0,81 & 0,81 & 0,93 & 0,75 & 0,85 & 1,00 & 0,85 & 0,85 & 0,93 & 0,79 \\
\hline$<10$ & 1 & Crianças/Adolescentes & 0,78 & & 0,73 & 0,74 & & 0,74 & 0,74 & & 0,69 & 0,78 & & 0,78 & 0,78 & & 0,73 \\
\hline & & Adultos & 0,56 & & 0,52 & 0,52 & & 0,52 & 0,52 & & 0,48 & 0,56 & & 0,56 & 0,56 & & 0,52 \\
\hline & & Global & & & 0,72 & & & 0,74 & & & 0,69 & & & 0,72 & & & 0,67 \\
\hline
\end{tabular}

Legenda: V (Vulnerabilidade); D (Dano); R (Risco). 


\section{CONCLUSÃO}

O presente artigo dispôs como objetivo principal aplicar uma metodologia semiquantitativa do risco microbiológico para implementar ApR num campo de golfe. Com a crescente escassez de água, as águas residuais tratadas são cada vez mais atraentes para atender às necessidades de água $e$, assim, contribuir para a utilização de fontes de água alternativas.

$\mathrm{O}$ risco microbiológico é intrínseco à $\mathrm{ApR}$ a partir de águas residuais. Para minimizar esse impacto, a gestão do risco que passa por uma primeira etapa de análise e uma segunda etapa de gestão do risco é essencial. Entretanto a AQRM é complexa e requer dados que muitas vezes a gestão não dispõe. Dessa forma, conclui-se que a metodologia semi-quantitativa do risco microbiológico para os diferentes tipos de reutilização, exceto reutilização potável, é plenamente aplicável e satisfatória.

A sua aplicação permite a elaboração de diferentes cenários que levam em consideração alta subjetividade, embora forneçam valores do risco credíveis e comparáveis aos graus (desprezável, aceitável e inaceitável). Assim resultam da MSqRM um conjunto de valores do risco por recetor e global, que permitirão a divulgação da possibilidade de utilização da rega de espaços de lazer e prática desportiva recorrendo a $\mathrm{ApR}$, contribuindo ainda para uma aceitação social desta fonte alternativa de água que se pretende crescente.

No presente trabalho calculou-se o risco microbiológico na implementação de ApR na rega do campo de golfe na cidade de Amarante, envolvendo os cenários de exposição associados a essa prática, quatro recetores (trabalhadores, jogadores e visitantes dividindo-se em crianças/adolescentes e adultos) e três barreiras (rega por aspersão; pós-cloragem; restrição de acesso durante as horas de rega no campo de golfe sem horário específico).

Numa primeira abordagem, os valores do risco por recetores variaram entre 3,92 e 6,37, correspondentes a um risco global com um valor de 5,43, classificado como aceitável. De seguida, apresentaram-se cinco reavaliações dos valores do risco dos diferentes recetores e global, correspondentes a diferentes combinações de alteração de barreiras, do encamisamento do sistema de rega e do acréscimo da capacitação dos trabalhadores e utilização de EPI's. Por fim, sugeriu-se a utilização simultânea dessas três características, resultando numa reavaliação que conduziu a menores valores do risco aferidos. Os resultados das várias alternativas apresentadas permitirão aos tomadores de decisão avaliar os prós e contras de cada uma e, optar, por aquela que corresponde à melhor solução na implementação de ApR num campo de golfe. Assim, conclui-se que o presente estudo apresenta uma excelente ferramenta técnica de decisão que permite avaliar custos envolvidos às barreiras $e$ risco estimado.

\section{REFERÊNCIAS}

ALVES, Nuno J. D. Implementação de sistema de reutilização de águas residuais para rega de zonas verdes com elevado contacto humano. Dissertação de Mestrado, Universidade Nova de Lisboa, 2008.

ANGELAKIS, A. N.; ASANO, T.; BAHRI, A.; JIMENEZ, B. E. e TCHOBANOGLOUS, G. Water reuse: From ancient to modern times and the future. Frontiers in Environmental Science, v. 6, 2018. Disponível em: https://doi.org/10.3389/fenvs.2018.00026. Acessado em: 11 de maio de 2018.

APA - AGÊNCIA PORTUGUESA DO AMBIENTE. Guia para a Reutilização de Água - Usos não potáveis. Lisboa: APA, 2019. Disponível em: https://doi.org/10.1007/s12250-012-3258-5.

ASANO, T. Water Reuse Issues, Technologies, and Applications. In Metcalf \& Eddy, v. 7, 2015.

CATARINO, ANA R. F. Reutilização de águas residuais tratadas para rega paisagística. $\mathrm{O}$ caso de estudo do Parque Tejo. Dissertação de Mestrado, Instituto Superior Técnico, Lisboa, 2018. Disponível em: https://fenix.tecnico.ulisboa.pt/downloadFile/112629504 3835831.

CHHIPI-SHRESTHA, G; HEWAGE, K. e SADIQ, R. Microbial quality of reclaimed water for urban reuses: Probabilistic risk-bases investigation and recommendations. Science of the Total Environment, v. 576, p. 738-751, 2017. Disponível em: http://dx.doi.org/10.1016/j.scitotenv.2016.10.105.

DOUNG, K. e SAPHORES, Jean-Daniel M. Obstacles to wastewater reuse: an overview. Wiley International Journal of Water Resources Development, v. 2, p. 199214, $2015 . \quad$ Disponível em: https://doi.org/10.1002/wat2.1074. Acessado em: maio/junho de 2015.

ERSAR - ENTIDADE REGULADORA DOS SERVIÇOS DE ÁGUA E RESÍDUOS. Reutilização de águas residuais. In Série GUIAS TÉCNICOS (Vol. 14). Lisboa: ERSAR, $2019 . \quad$ Disponível em 
http://www.ersar.pt/_layouts/mpp/file-

download.aspx?fileld=659599.

ISO - INTERNATIONAL ORGANIZATION FOR STANDARDIZATION. Guidelines for treated wastewater use for irrigation projects - Part 1: The basis of a reuse project for irrigation. Second edition. Geneva, Switzerland: ISO, 2020.

MAHESHWARI, B.; SINGH, V. e THORADENIYA, B. Balance Urban Development: Options and Strategies for Liveable Cities. Water Science and Technology Library, v. $\quad$ 2016. Disponível em: https://library.oapen.org/bitstream/handle/20.500.12657 /28107/1001887.pdf?sequence=1.

MUJERIEGO R. e SALA L. (1991). Golf course irrigation with reclaimed wastewater. Water Science and Technology, 24, 161-171. Disponível em: https://iwaponline.com/wst/articleabstract/24/9/161/24292.

PORTUGAL. Decreto Lei n. -119 de 21 de agosto de 2019. Estabelece o regime jurídico de produção de água para reutilização, obtida a partir do tratamento de águas residuais, bem como da sua utilização. Lisboa, 2019.

PEREIRA, Ana. C. D. Avaliação de desempenho operacional de estações de tratamento de águas residuais como instrumento associado à reutilização da água na rega de campos de Golfe. Dissertação de Mestrado, Universidade Do Algarve, 2009.

PEREIRA, A.; ROSA, M. J. e QUADROS, S. Proposta de uma Abordagem para Avaliação e Controlo dos Riscos Associados ao Tratamento de Águas Residuais Urbanas para Utilização na Rega de Campos de Golfe. ENaSB\SILUBESA, 2010.

PETTYGROVE, G. S. e ASANO, T. Irrigation with reclaimed municipal wastewater. GeoJournal, p. 273282, $1987 . \quad$ Disponível em: https://doi.org/10.2134/jeq1986.0047242500150003002 $4 \mathrm{x}$.

REBELO, A. (2018) Reutilização de água: Abordagem para o desenvolvimento de práticas de reutilização de água. In Atas do 14º Congresso da Água, Évora, 2018.
REBELO, A.; QUADRADO, M.; FRANCO, A.; LACASTA, N. e MACHADO, P. Water reuse in Portugal: New legislation trends to support the definition of water quality standards based on risk characterization. Water Cycle 1, p. 41-53, 2020. Disponível em: https://doi.org/10.1016/j.watcyc.2020.05.006. Acessado em: 18 de junho de 2020.

SANTOS, A e VIEIRA, J. Reúso de Água para o Desenvolvimento Sustentável: Aspectos de Regulamentação no Brasil e em Portugal. Revista Eletrônica de Gestão e Tecnologias Ambientais (GESTA), v. 8, p. 50-68, 2020. Disponível em: http://dx.doi.org/10.9771/gesta.v8i1.36462. Acessado em: julho de 2020.

SANTOS, Maria M. C. Reutilização de águas residuais urbanas tratadas. Dissertação de Mestrado em Engenharia Do Ambiente. Faculdade de Ciências e Tecnologia - Universidade Nova de Lisboa, 2008.

THE EUROPEAN WATER ASSOCIATION (EWA) $\mathrm{e}$ ASSOCIAÇÃO PORTUGUESA PARA ESTUDOS DE SANEAMENTO BÁSICO (APESB). Sistemas de Águas Residuais Urbanas - Um Guia para não Especialistas, 1998. Stephen D. Myers.

USEPA - UNITED STATES ENVIRONMENTAL PROTECTION AGENCY. Guidelines for Water Reuse. Development, v. 26, p. 252. Washington DC: USEPA, $2004 . \quad$ Disponível em: http://www.epa.gov/nrmrl/pubs/625r04108/625r04108.p df

WEBSITE OFICIAL DO CGA. Disponível em: https://golfedeamarante.com/.

WHO - WORLD HEALTH ORGANIZATION. Quantitative Microbial Risk Assessment: Application for Water Safety Management. WHO Press, p. 187. Geneva, Switzerland: WHO, 2016. Disponível em: http://www.who.

WWAP - WORLD WATER ASSESSMENT PROGRAMME. Wastewater the Untapped Resource. In Journal of Chemical Information and Modeling. Paris, France: WWAP, 2017. Disponível em: https://doi.org/10.1017/CBO9781107415324.004. 